\title{
Effect modification by gender and smoking status on the association between obesity and atopic sensitization in Chinese adults: a hospital-based case-control study
}

\author{
Xiao Luo', Yupeng Wang ${ }^{1}$, Zhiqiang Wang ${ }^{2}$, Xiao-hua Zhou³, Jing Zhao', Jianing Suo ${ }^{1}$, Xiaohui Dong ${ }^{1}$ \\ and Meina Liu ${ }^{1 *}$
}

\begin{abstract}
Background: There is an ongoing debate on the potential association between obesity and atopy. However, no previous studies have investigated whether this relationship depends on sex and smoking status in Chinese adults.

Methods: In this hospital-based, case-control study, we recruited 1150 atopic cases aged 18 years or older and 1245 healthy control participants during April 2009 and December 2012 in Harbin, China. We conducted structured questionnaire interviews, anthropometry measurements and serum allergen-specific immunoglobulin E (lgE) testing. Univariate and multivariate logistic regression models were used to explore the relationship between obesity and atopy risk stratified by sex and smoking status.

Results: There was an association between obesity and an increased risk of atopic sensitization after adjusting for age, educational, family history, smoking and alcohol consumption (OR: 2.61, 3.25; 95\% Cl: 1.57-4.33,1.91-5.56 in males and females, respectively). The association between $\mathrm{BMI}$ and allergic sensitization depended on smoking status. In both genders, the association of obesity with atopic sensitization risk was stronger in non-smokers than in current smokers. In males, ORs of atopic sensitization for obesity were 3.15 (95\% Cl, 1.46-6.68) for non-smokers and 2.22 (95\% Cl, 1.10-4.48) for current smokers. The corresponding ORs in females were 3.51 (95\% Cl, 1.98-6.24) and 2.22 (95\% Cl, 0.46-10.68) for non-smokers and current smokers, respectively. After excluding those subjects who with pre-existing allergic conditions, the same relationship still remained.

Conclusions: Obesity is positively and significantly associated with the risk of atopy in both men and women as well in both smokers and non-smokers in China. In addition, the relationship between obesity and atopic sensitization is stronger in non-smokers than in current smokers.
\end{abstract}

Keywords: Obesity, Body mass index, Atopy, Adult

\section{Background}

The prevalence of allergic diseases has increased in recent years [1-3], especially in low and middle income countries like China [4,5]. Atopy refers to a hereditary predisposition of some individuals to develop immunoglobulin $\mathrm{E}$ antibodies (IgE) to common allergens [6], commonly preceding the development of allergic diseases [7] and usually

\footnotetext{
*Correspondence: liumeina369@163.com

'Public Health College, Harbin Medical University, 157 Baojian Road, Harbin City, Heilongjiang Province Postcode 150081, P.R. China

Full list of author information is available at the end of the article
}

defined as having detectable allergen specific IgE either by serum IgE tests, skin prick tests or other laboratory examinations. Considering the rapid rise of allergic disorders, understanding the associations of potential factors with atopic sensitization has important clinical and public health implications.

Obesity has been linked to the increase risk of atopic sensitization in some epidemiological studies [8-12], while other studies demonstrated that there is no association between obesity and atopic sensitization [13-17]. The reasons for these contradictory findings might be due to differences

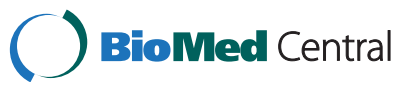

(C) 2014 Luo et al.; licensee BioMed Central Ltd. This is an Open Access article distributed under the terms of the Creative Commons Attribution License (http://creativecommons.org/licenses/by/2.0), which permits unrestricted use, distribution, and reproduction in any medium, provided the original work is properly credited. The Creative Commons Public Domain Dedication waiver (http://creativecommons.org/publicdomain/zero/1.0/) applies to the data made available in this article, unless otherwise stated. 
in obesity definitions, laboratory methods, populations and sample sizes. For instance, in a study of Chinese men and women, no association was found between body mass index (BMI) and allergic sensitization, whereas percent body fat (\%BF) was found to be associated with a higher rate of allergic sensitization in men but no associations between \%BF and any sensitization in women [10]. In another study, obesity was associated with a higher risk of atopy, and this association was largely driven by food sensitization [12]. Some studies have found association between obesity and allergic sensitization, while others have not. Gender might also play an important role in the association between obesity and atopic sensitization. From a biological view, sex hormone may contribute to the increased risk of atopy [18]. Moreover, females have higher amount of body fat than males [19], which might increase the risk of atopic sensitization in females, but epidemiological evidence is still inconsistent $[9,10]$. Therefore, it is necessary to clarify the relationship between obesity and atopic sensitization stratified by gender.

Cigarette smoking may reduce atopic sensitization, and this association was confirmed in several crosssectional and longitudinal studies, even though some bias cannot be ruled out such as healthy smoker bias and self-selection bias [20-27]. Consistent with previous studies, a 32-year well designed population-based cohort study supported the hypothesis that the suppressive effects on immune system of smoking protect against atopy [27]. Therefore, the negative relationship between smoking and the incidence of allergic sensitization could partly explained by an immunosuppressive effect. Considering that adipose tissue can also be involved in inflammatory processes [28], there might be a complex relation between body weight and smoking status, which could affect the incidence of allergic sensitization. On the one hand, due to the increased metabolic rate [29-31] or restricting caloric absorption [32], body weight in current smokers is generally less than that in never smokers. This may reduce the risk of obese individuals with increased atopic sensitization. On the other hand, ex-smokers often gain weight after smoking cessation [33-36], which may cause a higher risk of atopic sensitization. Therefore, the association between body weight and atopic sensitization may be modified by smoking status. However, as far as we know, no previous studies have examined the relationship between obesity and IgE-mediated allergen sensitization by smoking status in Chinese adults.

In this hospital-based case control study, we aimed to investigate the association between obesity and atopic sensitization among Chinese adults. We are particularly interested in exploring this association between obesity and atopy stratified by gender and smoking status. Understanding whether the association between obesity and atopy depends on gender and smoking status is important for developing tailored intervention strategies.

\section{Methods}

\section{Study participants}

This is a hospital-based, case-control study conducted at the Allergy Department of First Affiliated Hospital of Harbin Medical University in Harbin, China. Written informed consents were obtained from all subjects involving in this study. This study was approved by the Human Ethics Review Board, Harbin Medical University. (Reference number is HMUIRB20120019).

From April 2009 to December 2012, all subjects who visited the Department of Allergy in the First Affiliated Hospital of Harbin Medical University underwent the specific IgE testing regardless of their pre-existing conditions. Those aged 18 years or older were eligible for this study. Cases and controls were identified based on the results of the specific IgE testing. We identified cases including those who were newly diagnosed atopy based on positive specific IgE testing to at least 1 of the 13 most common local aeroallergens and food allergens. Those cases who had been previously diagnosed with allergic conditions were also confirmed positive in at least one of the IgE tests. Potential controls included healthy adults who visited the same department of the hospital for a health check-up during the same period. Final eligible controls were those who were negative in all specific IgE tests, and had not been previously diagnosed of any allergic diseases (included allergic eczema, allergic asthma, allergic rhinitis and food allergy). Among cases and controls, athletes, those currently undergoing professional anaerobic training, and pregnant or breastfeeding women were excluded because their obesity status could not be appropriately determined using body mass index. Subjects who did not take serum allergen-specific IgE testing, were not willing to complete the questionnaire interview or anthropometry measurements were also excluded from the study. In addition, we excluded those subjects who were ex-smokers due to small number of ex-smokers(men, 25 cases and 44 controls; women, 13 cases and 16 controls) for estimating the association between obesity and atopic sensitization. Finally, our analysis included the data from 2395 participants (1150 atopic subjects and 1245 non-atopic subjects).

\section{Questionnaire}

A face-to-face interview was conducted by trained interviewers. One page questionnaire included personal demographic factors (sex, age, educational level), family history (parents, siblings, and children with related diseases including allergic asthma, allergic rhinitis, allergic eczema and food allergy), smoking status and alcohol consumption. Age was calculated as the difference between the year of 
birth and the year of interview. Educational level was categorized into three groups: illiterate/elementary school, junior/senior high school, and college, university or higher. Current smokers were defined on the basis of the World Health Organization criteria, as those who self-reported smoking every day for at least 6 months [37]. Regular alcohol drinkers were defined as drinking more than twice per week for at least one year.

\section{BMI calculation and classification}

According to a standard protocol [38], we measured weight and height of all participants. Subjects were required to dress in normal indoor clothing and without shoes, weighed to the nearest $0.1 \mathrm{~kg}$ using a calibrated standard scale. Height was measured to the nearest $0.1 \mathrm{~cm}$ using a stadiometer (Detecto-Scales; Brooklyn, NY). The physician who conducted anthropometry did not know the purpose of this study. BMI was calculated as weight $(\mathrm{kg}) /$ [height $(\mathrm{m})]^{2}$. All subjects were grouped into one of the following three groups, normal weight $(\mathrm{BMI}<24)$, overweight $(\mathrm{BMI} \geq 24$ and $\mathrm{BMI}<28)$ and obesity $(\mathrm{BMI} \geq 28)$ according to the criteria established in 2003 by the Working Group on Obesity in China [39].

\section{Allergen-specific IgE testing and atopy}

Serum samples were tested for allergen-specific IgE using the AllergyScreen system (Mediwiss Analytic GmbH, Germany). The choice of allergens was based on the epidemiology of atopic sensitization in China. The thirteen most common allergens in the northeast of China were assessed, including seven aeroallergens and six food allergens. Aeroallergens include Dermatophagoides pteronyssinus, common ragweed and mugwort, Hop, cat and dog fur, mould mixture (Penicillium notatum, Cladosporium herbarum, Aspergillus fumigatus, Alternaria alternate), tree pollen mixture (Robur, Elm, London Plane, Willow, Cottonwood) and German cockroach. Food allergens include egg white/egg yolk, fish, crab, shrimp, milk and beef. Atopy was defined as if the concentration of a least one allergen-specific IgE was $0.35 \mathrm{kU} / \mathrm{L}$ or greater.

\section{Statistical analysis}

The baseline characteristics of cases and controls were examined. Age was categorized into three groups: 1839,40-59, $\geq 60$ years. The associations of categorical variables with atopy were estimated using chi-squared tests. To assess the associations of obesity with atopic sensitization and to control for the potential confounding factors, crude and adjusted odds ratio (OR) and their 95\% confidence intervals (CI) were calculated using logistic regressions. Separate analyses were conducted for different genders and smoking status. A two-sided $p$ value of less than 0.05 was taken to indicate statistical significance for all estimates. The effect modifications of gender and smoking status on a multiplicative scale were assessed by including interaction terms between BMI and gender or smoking status in logistic regression models. A $p$ value for the interaction term of less than 0.10 was considered evidence of interaction. Stratified models were used to assess the associations between BMI and atopy where evidence for interaction was found. The $p$ values for linear trends were calculated by entering the ordinal variable of BMI as a continuous term in the regression model. All analyses were performed using statistical SAS 9.1 (SAS Inc., Cary, NC, USA).

\section{Results}

In the present study, a total of 2395 participants were recruited, including 361 men cases and 384 men controls, 789 women cases and 861 women controls. The numbers and percentage of demographic characteristics, smoking status of cases and controls by gender are shown in Table 1 . Both men and women cases were more likely to have higher educational level than controls and to have higher proportion of obesity than controls. In addition, controls were more likely than cases to be older in men. However, age difference was not seen in women. With regard to family allergic disease history, smoking status and regular alcohol drinking status, the differences between atopic sensitization group and non-atopic sensitization group were not statistically significant.

Table 2 shows the associations between BMI classification and atopic sensitization in males and females. The strength of the association between obesity and atopic sensitization depended on sex with a significant sex-BMI interaction term $\left(p_{\text {effect modification }}=0.0414\right)$. Compared to men with normal BMI, obese men had a notably increased risk of atopic sensitization after adjusting for age, educational, family history, smoking and alcohol consumption (OR, 2.61; 95\% CI, 1.57-4.33). This association is stronger in women (OR, 3.25; 95\% CI, 1.91-5.56), after adjusting for the same set of confounding factors. In order to exclude allergic induced obesity, such as those with reduced physical activity or side reaction of therapy related to allergic diseases, we excluded subjects with previously diagnosed allergic diseases. The strength of association between BMI and atopic sensitization varied between men and women. Obesity was positively associated with atopic sensitization with $\mathrm{OR}=2.76$ (95\% CI, 1.54-4.95) in men, 2.93 (95\% CI, 1.59-5.40) in women. Interestingly, overweight women had a lower risk of atopic sensitization than women with normal BMI with $\mathrm{OR}=0.76$ (95\% CI, 0.60-0.96). Even after adjusting for other confounding factors, this association still existed (OR, 0.76; 95\% CI, 0.59-0.97). However, when we excluded those women with prior allergic diseases, this association was no longer statistically significant at the $5 \%$ level (OR, 0.76; 95\% CI, 0.56-1.02). 
Table 1 Characteristics of atopic sensitization cases and hospital health controls in men and women

\begin{tabular}{|c|c|c|c|c|c|c|}
\hline & \multicolumn{2}{|l|}{ Men } & \multirow{3}{*}{$P$ value } & \multicolumn{2}{|l|}{ Women } & \multirow{3}{*}{$P$ value } \\
\hline & Case & Control & & Case & Control & \\
\hline & $\mathrm{N}(\%)$ & N (\%) & & N (\%) & $\mathrm{N}(\%)$ & \\
\hline $\mathbf{N}$ & 361 & 384 & & 789 & 861 & \\
\hline Age (years) & & & 0.0286 & & & 0.0778 \\
\hline $18-39$ & $212(58.73)$ & $189(49.22)$ & & $435(55.13)$ & $433(50.29)$ & \\
\hline $40-59$ & $128(35.46)$ & $163(42.45)$ & & $315(39.92)$ & $391(45.41)$ & \\
\hline$\geq 60$ & $21(5.82)$ & $32(8.33)$ & & $39(4.94)$ & $37(4.30)$ & \\
\hline Educational level & & & 0.0004 & & & $<0.0001$ \\
\hline $1 \mathrm{st}$ & $88(24.38)$ & $60(15.63)$ & & $176(22.31)$ & $105(12.20)$ & \\
\hline 2nd & $129(35.73)$ & $188(48.96)$ & & $313(39.67)$ & $492(57.14)$ & \\
\hline $3 r d$ & $144(39.89)$ & $136(35.42)$ & & $300(38.02)$ & $264(30.66)$ & \\
\hline Family allergic disease history & & & 0.6750 & & & 0.6302 \\
\hline No & $304(84.21)$ & $319(83.07)$ & & $628(79.59)$ & $677(78.63)$ & \\
\hline Yes & $57(15.79)$ & $65(16.93)$ & & $161(20.41)$ & $184(21.37)$ & \\
\hline Smoking status & & & 0.6383 & & & 0.8020 \\
\hline No & $212(58.73)$ & $232(60.42)$ & & $739(93.66)$ & 809 (93.96) & \\
\hline Current smoking & $149(41.27)$ & $152(39.58)$ & & $50(6.34)$ & $52(6.04)$ & \\
\hline Regular alcohol drinkers & & & 0.6501 & & & 0.8944 \\
\hline No & $216(59.83)$ & $236(61.46)$ & & $748(94.80)$ & 815 (94.66) & \\
\hline Yes & $145(40.17)$ & $148(38.54)$ & & $41(5.20)$ & $46(5.34)$ & \\
\hline BMI & & & 0.0016 & & & $<0.0001$ \\
\hline Normal & $178(49.31)$ & $224(58.33)$ & & $582(73.76)$ & $629(73.05)$ & \\
\hline Overweight & $129(35.73)$ & $132(34.38)$ & & $149(18.88)$ & $212(24.62)$ & \\
\hline Obesity & $54(14.96)$ & $28(7.29)$ & & $58(7.35)$ & $20(2.32)$ & \\
\hline
\end{tabular}

Table 2 ORs and $95 \%$ Cls for atopy in relation to BMI category stratified by sex in all subjects and those without allergic diseases

\begin{tabular}{|c|c|c|c|c|c|c|c|c|}
\hline \multicolumn{4}{|l|}{ Men } & \multicolumn{4}{|c|}{ Women } & \multirow{2}{*}{$\begin{array}{l}\text { Effect } \\
\text { modification }\end{array}$} \\
\hline Case & Control & $\operatorname{cOR}(95 \% \mathrm{Cl})^{\mathrm{a}}$ & aOR $(95 \% \mathrm{CI})^{\mathrm{b}}$ & Case & Control & $\operatorname{cOR}(95 \% \mathrm{Cl})^{\mathrm{a}}$ & aOR $(95 \% \mathrm{CI})^{\mathrm{b}}$ & \\
\hline N (\%) & N (\%) & & & N (\%) & N (\%) & & & P value ${ }^{c}$ \\
\hline
\end{tabular}

\begin{tabular}{|c|c|c|c|c|c|c|c|c|c|}
\hline \multicolumn{10}{|c|}{ All participants } \\
\hline Normal & $178(49.31)$ & $224(58.33)$ & 1.00 (ref) & 1.00 (ref) & $582(73.76)$ & $629(73.05)$ & 1.00 (ref) & 1.00 (ref) & \\
\hline Overweight & 129 (35.73) & 132 (34.37) & $1.23(0.90-1.68)$ & $1.29(0.93-1.79)$ & 149 (18.88) & $212(24.62)$ & $0.76(0.60-0.96)$ & $0.76(0.59-0.97)$ & 0.0414 \\
\hline Obesity & $54(14.96)$ & $28(7.29)$ & $2.43(1.47-3.99)$ & $2.61(1.57-4.33)$ & $58(7.35)$ & $20(2.32)$ & $3.13(1.86-5.28)$ & $3.25(1.91-5.56)$ & \\
\hline$P$ trend & & & & $p=0.0003$ & & & & $p=0.0909$ & \\
\hline \multicolumn{10}{|c|}{$\begin{array}{l}\text { Without allergic } \\
\text { diseases }\end{array}$} \\
\hline Normal & $97(47.55)$ & $224(58.33)$ & 1.00 (ref) & 1.00 (ref) & 334 (73.89) & $629(73.05)$ & 1.00 (ref) & 1.00 (ref) & \\
\hline Overweight & $76(37.25)$ & $132(34.37)$ & $1.33(0.92-1.92)$ & $1.41(0.95-2.08)$ & 89 (19.69) & $212(24.62)$ & $0.79(0.60-1.05)$ & $0.76(0.56-1.02)$ & 0.0641 \\
\hline Obesity & $31(15.20)$ & $28(7.29)$ & $2.56(1.46-4.49)$ & $2.76(1.54-4.95)$ & $29(6.42)$ & $20(2.32)$ & $2.73(1.52-4.90)$ & $2.93(1.59-5.40)$ & \\
\hline$P$ trend & & & & $p=0.0006$ & & & & $p=0.3106$ & \\
\hline
\end{tabular}

${ }^{\mathrm{a}} \mathrm{COR}$, crude odds ratio; $\mathrm{Cl}$, confidence interval.

baOR, adjusted odds ratio; $\mathrm{Cl}$, confidence interval.

${ }^{b}$ Adjusted for age, educational levels, family allergic diseases history, smoking status and alcohol consumption.

${ }^{\mathrm{C}} \mathrm{P}$ value for effect modification by sex on the association of BMI category and atopic sensitization after adjustment. 
Considering the different smoking rate between males and females, we assessed the associations between BMI category and atopy risk stratified by smoking status for males and females separately. The association estimates between BMI category and atopic sensitization risk stratified by smoking status in each gender are shown in Table 3. In men, the associations between BMI category and atopic risk were statistically significant in non-smokers $(p$ trend $=0.0245)$ and current smokers $(p$ trend $=0.0042)$ while in women these trends were not statistically significant. Smoking status modified the effect of BMI category on atopy risk ( $p_{\text {effect modification }}=0.0349$ and 0.0260 for men and women, respectively). The OR of atopic sensitization for obesity in men was slightly lower in current smokers (2.22; 95\% CI, 1.10-4.48) than that in never smokers (3.15; 95\% CI, 1.49-6.68). Obesity was positively associated with atopy (OR, 3.51; 95\% CI, 1.98-6.24) in never smoking women, but was not statistically significant in current smokers (OR, 2.22; 95\% CI, 0.46-10.68). Nevertheless, the point estimates of OR indicated that obesity doubled the odds of allergic sensitization regardless of their gender and smoking status.

Table 4 presents the association estimates of BMI category with atopic sensitization according to gender and smoking status in those without existing allergic diseases. Among current smoking men, BMI category was significantly related with atopic sensitization $(p$ trend $=0.0032)$. Among never smoking men, obesity was positively associated with atopic sensitization (OR, 3.29; 95\% CI, 1.37-7.95). In never smoking women, obesity was significantly associated with an increased atopic risk (OR, 3.00; 95\% CI, 1.565.76). The effect modification by smoking status on the association of BMI category and atopic sensitization was significant in men $\left(p_{\text {effect modification }}=0.0081\right)$ but not so in women $\left(p_{\text {effect modification }}=0.0901\right)$.

For those subjects who were only allergic to aeroallergens, the results of effect modification of smoking status on the association between obesity and allergic sensitization were similar with those of all subjects allergic to all allergens and subjects without allergic diseases (data not shown). In all subjects and those without allergic diseases, the effect of BMI category on atopic sensitization risk was still stronger in never smokers.

\section{Discussion}

In this hospital-based, case-control study, we demonstrated that not only obesity was associated with atopic sensitization in Chinese males and females, but also such an association was modified by smoking status. We found that the association between obesity and atopic sensitization was stronger in never smokers than in current smokers.

The findings on the association between obesity and atopy in adults in the literature are inconsistent. An epidemiological study of adults in Canada and the US has revealed a significant relationship between obesity and atopy in both women and men [8]. In another birth cohort study, Hancox et al. reported that a raised BMI is associated with allergic sensitization in women but not in men [9]. In contrast, some studies reported contradictory findings [13-17]. Those findings of other populations may not apply to Chinese because allergens, life style and other related factors (such as smoking rate and diet pattern) vary among different regions and cultures [40]. Those variations might have contributed to the inconsistent findings in different populations. In this study,

Table 3 ORs and $95 \%$ Cls for atopy in relation to BMI stratified by sex and smoking status in all subjects

\begin{tabular}{|c|c|c|c|c|c|c|c|c|c|}
\hline & \multirow[b]{2}{*}{$\begin{array}{l}\text { Case } \\
\text { N (\%) }\end{array}$} & \multicolumn{3}{|c|}{ Never smokers } & \multicolumn{4}{|c|}{ Current smokers } & \multirow{2}{*}{$\begin{array}{c}\text { Effect } \\
\text { Modificatior } \\
\text { P value }^{c}\end{array}$} \\
\hline & & $\begin{array}{c}\text { Control } \\
\text { N (\%) }\end{array}$ & $\operatorname{cOR}(95 \% \mathrm{Cl})^{\mathrm{a}}$ & aOR $(95 \% \mathrm{Cl})^{\mathrm{b}}$ & $\begin{array}{l}\text { Case } \\
\text { N (\%) }\end{array}$ & $\begin{array}{c}\text { Control } \\
\text { N (\%) }\end{array}$ & $\operatorname{cOR}(95 \% \mathrm{Cl})^{\mathrm{a}}$ & aOR $(95 \% \mathrm{Cl})^{\mathrm{b}}$ & \\
\hline Men & & & & & & & & & 0.0349 \\
\hline Normal & $102(48.11)$ & $118(50.86)$ & 1.00 (ref) & 1.00 (ref) & $76(51.01)$ & 106 (69.74) & 1.00 (ref) & 1.00 (ref) & \\
\hline Overweight & $82(38.68)$ & $102(43.97)$ & $0.93(0.63-1.38)$ & $1.02(0.67-1.55)$ & $47(31.54)$ & 30 (19.74) & $2.19(1.27-3.77)$ & $2.15(1.23-3.77)$ & \\
\hline Obesity & $28(13.21)$ & $12(5.17)$ & $2.70(1.31-5.58)$ & $3.15(1.49-6.68)$ & $26(17.45)$ & $16(10.53)$ & $2.27(1.14-4.51)$ & $2.22(1.10-4.48)$ & \\
\hline$P$ trend & & & & $p=0.0245$ & & & & $p=0.0042$ & \\
\hline Women & & & & & & & & & 0.0260 \\
\hline Normal & $549(74.29)$ & $587(72.56)$ & 1.00 (ref) & 1.00 (ref) & $33(66.00)$ & $42(80.77)$ & 1.00 (ref) & 1.00 (ref) & \\
\hline Overweight & 137 (18.54) & $205(25.34)$ & $0.72(0.56-0.91)$ & $0.70(0.54-0.91)$ & $12(24.00)$ & 7 (13.46) & $2.18(0.77-6.16)$ & $2.66(0.83-8.51)$ & \\
\hline Obesity & $53(7.17)$ & $17(2.10)$ & $3.33(1.91-5.83)$ & $3.51(1.98-6.24)$ & $5(10.00)$ & $3(5.77)$ & $2.12(0.47-9.53)$ & $2.22(0.46-10.68)$ & \\
\hline$P$ trend & & & & $p=0.2025$ & & & & $p=0.1047$ & \\
\hline
\end{tabular}

${ }^{\mathrm{a}} \mathrm{COR}$, crude odds ratio; $\mathrm{Cl}$, confidence interval.

baOR, adjusted odds ratio; $\mathrm{Cl}$, confidence interval.

${ }^{\mathrm{b}}$ Adjusted for age, educational levels, family allergic diseases history and alcohol consumption.

${ }^{\mathrm{C}} \mathrm{P}$ value for effect modification by smoking status on the association of BMI category and atopic sensitization in men and women, respectively. 
Table 4 ORs and $95 \%$ Cls for atopy in relation to BMI stratified by sex and smoking status in subject without allergic diseases

\begin{tabular}{|c|c|c|c|c|c|c|c|c|c|}
\hline & \multirow[b]{2}{*}{$\begin{array}{l}\text { Case } \\
\text { N (\%) }\end{array}$} & \multicolumn{3}{|c|}{ Never smokers } & \multicolumn{4}{|c|}{ Current smokers } & \multirow{2}{*}{$\begin{array}{c}\text { Effect } \\
\text { Modification } \\
\text { P value }^{c}\end{array}$} \\
\hline & & $\begin{array}{c}\text { Control } \\
\mathrm{N}(\%)\end{array}$ & $\operatorname{cOR}(95 \% \mathrm{Cl})^{\mathrm{a}}$ & aOR $(95 \% \mathrm{Cl})^{b}$ & $\begin{array}{l}\text { Case } \\
\text { N (\%) }\end{array}$ & $\begin{array}{c}\text { Control } \\
\mathrm{N}(\%)\end{array}$ & COR $(95 \% \mathrm{Cl})^{\mathrm{a}}$ & aOR $(95 \% \mathrm{Cl})^{b}$ & \\
\hline Men & & & & & & & & & 0.0081 \\
\hline Normal & $50(47.62)$ & $118(50.86)$ & 1.00 (ref) & 1.00 (ref) & $47(47.47)$ & 106 (69.74) & 1.00 (ref) & 1.00 (ref) & \\
\hline Overweight & 41 (39.05) & $102(43.97)$ & $0.95(0.58-1.55)$ & $0.98(0.58-1.65)$ & 35 (35.35) & $30(19.74)$ & $2.63(1.45-4.78)$ & $2.50(1.34-4.65)$ & \\
\hline Obesity & $14(13.33)$ & $12(5.17)$ & $2.75(1.19-6.37)$ & $3.29(1.37-7.95)$ & $17(17.17)$ & $16(10.53)$ & $2.40(1.12-5.15)$ & $2.44(1.10-5.38)$ & \\
\hline$P$ trend & & & & $p=0.0671$ & & & & $p=0.0032$ & \\
\hline Women & & & & & & & & & 0.0910 \\
\hline Normal & $313(74.35)$ & $587(72.56)$ & 1.00 (ref) & 1.00 (ref) & $21(67.74)$ & $42(80.77)$ & 1.00 (ref) & 1.00 (ref) & \\
\hline Overweight & $82(19.48)$ & 205 (25.34) & $0.75(0.56-1.00)$ & $0.71(0.52-0.96)$ & 7 (22.58) & $7(13.46)$ & $2.00(0.62-6.45)$ & $2.35(0.62-8.95)$ & \\
\hline Obesity & $26(6.17)$ & $17(2.10)$ & $2.87(1.53-5.37)$ & $3.00(1.56-5.76)$ & $3(9.68)$ & $3(5.77)$ & $2.00(0.37-10.77)$ & $3.60(0.47-27.58)$ & \\
\hline$P$ trend & & & & $p=0.5483$ & & & & $p=0.1026$ & \\
\hline
\end{tabular}

${ }^{a} \mathrm{COR}$, crude odds ratio; $\mathrm{Cl}$, confidence interval.

baOR, adjusted odds ratio; $\mathrm{Cl}$, confidence interval.

${ }^{\mathrm{b}}$ Adjusted for age, educational levels, family allergic diseases history and alcohol consumption.

${ }^{\mathrm{C}} \mathrm{P}$ value for effect modification by smoking status on the association of BMI category and atopic sensitization in men and women without allergic diseases, respectively.

our findings support a positive association between obesity and atopic sensitization in Chinese adults. Additionally, our findings also support a possible sex difference in the relationship between obesity and atopic sensitization which is consistent with a previous study [9]. In our study, OR for obesity was greater in women than in men, but even in men obesity increased risk of allergic sensitization was more than 2 folds. However, our findings are inconsistent with those of another study conducted in China [10], in which no association between BMI category and allergic sensitization was found but percent body fat was found to be associated with a higher rate of allergic sensitization in men than women. The different findings might be due to the differences in the age of study subjects, the panel of allergens and the original objectives between our study and theirs.

Although there are some limitations with the hospital case-control study design, our finding on the relationship between obesity and atopic sensitization being modified by smoking status is intriguing. It suggests the possibility that the association between obesity and atopic sensitization is influenced by smoking status. We demonstrated that the effects of obesity were modified by smoking status in both genders. However, obese adults had more than doubled the odds of having atopic sensitization compared to those with normal BMI regardless of their gender and smoking status. Such associations were not substantially altered in the case of excluding subjects with previously existing allergic diseases. It is not clear why smoking alters the association between obesity and atopic sensitization. There are several possible interpretations. First, current smokers are likely to have lower BMI than non-smokers due to the increased metabolic rate [29-31] or restricting caloric absorption [32], which might reduce the effect of obesity on atopic sensitization risk. Second, a common component of cigarette smoke, such as nicotine, have been shown to suppress various parameters of the immune system $[41,42]$. The decreased risk of atopic sensitization in smokers might result partially from the suppressive effects of the components of tobacco on the immune system. Additionally, cigarette smoking could influence atopic sensitization by an indirect mechanism. For example, current smokers might be more likely to have some respiratory tract symptoms, such as chronic cough. It is possible that pathogenic bacteria could alter immune function and affect the incidence of allergic sensitization. Further studies are required to explore the true mechanisms underlying the interaction between obesity and smoking on atopic sensitization. Considering the harmful effect of cigarette smoke, smoking is not encouraged in preventing atopic disorders.

More interestingly, we found that overweight is associated with an increased risk of atopy in current smoking men. Our results should be interpreted with caution. It is worth noticing that BMI is not a perfect measure of excess body fat [43], even though we excluded subjects for whom BMI was not ideal to capture adiposity levels. The power of BMI to distinguish between muscle and excess fat might be limited, which could lead to misclassification of overweight and mild obesity [44]. Moreover, smoking is associated with a decrease in body weight, which might contribute to the observed relationship between overweight and atopy in current smoking men and women. 
The strengths of our study include a relatively large sample size of men and women cases and controls, which enable us to look at the effect modification by sex and smoking status on the association of obesity with atopic sensitization. Moreover, obesity was defined according to the current Chinese standard, which could better capture the link between BMI and atopic sensitization in Chinese population. In addition, we were able to assess that the association between obesity and atopic sensitization according to smoking status for the first time.

Our study also had several limitations. First, we did not measure the waist circumference (WC) or the waistto-hip ratio (WHR). Those measurements are considered to have better correlated with tobacco smoking than BMI [45]. Nevertheless, BMI has been traditionally used as a surrogate measure of adiposity and is the most frequently used diagnostic tool for obesity. Therefore, our findings largely reflect the associations between obesity and allergic sensitization in Chinese population. Second, sample sizes for subgroup analyses for men and women could decrease the power to detect associations. Although we have a relatively large sample size, some subgroup had small numbers of subjects and effect estimates should be interpreted with caution as reflected in the wide confidence intervals. Third, as an observational case-control study, we could not establish a causal link between smoking on the association between obesity and atopy. In addition, selection bias in this study might exist. Atopic patients who came to the allergy department in this hospital were more likely to have a severe symptom of atopy. Finally, we did not obtain data on some important potential confounders, such as physical activity, an important factor for body weight. Since our study was conducted in a single hospital in Harbin, China, the generalizability of our findings to Chinese in other regions or to other populations remains to be further assessed.

\section{Conclusions}

Obesity is significantly associated with the risk of atopic sensitization in male and female adults in China. In addition, smoking status modified the effect of BMI on atopy risk. Although the association between BMI category and atopic sensitization is less strong in current smokers than in non-smokers, obesity increases the risk of atopic sensitization for obesity by more than two folds regardless of their gender and smoking status. Our findings have important public implications for developing strategies of preventing allergic sensitization.

\section{Abbreviations}

BMI: Body mass index; \%BF: Percent body fat; IgE: Immunoglobulin E; SlgE: Specific immunoglobulin E; OR: Odds ratio; cOR: Crude odds ratio; aOR: Adjusted odds ratio; Cl: Confidence Intervals; WC: Waist circumference; WHR: Waist-to-hip ratio.
Competing interests

The authors declare that they have no competing interests.

\section{Authors' contributions}

$X L, M L$ and $Z W$ conceived the study idea and participated in its design. $X L, Y W, J Z$, JS and $X D$ participated in the study design and conduct of data collection. $\mathrm{XL}, \mathrm{ML}, \mathrm{ZW}$ and $\mathrm{XZ}$ carried out statistical analysis. All authors contributed to the writing of the manuscript and critically reviewed the final version submitted for publication. All authors read and approved the final manuscript.

\section{Acknowledgements}

This study was funded by the National Science and Technology Major Project of the Ministry of Science and Technology of China (2011ZX08011-005 and 2012ZX08011-005).

\section{Author details}

${ }^{1}$ Public Health College, Harbin Medical University, 157 Baojian Road, Harbin City, Heilongjiang Province Postcode 150081, P.R. China. ${ }^{2}$ School of Medicine, the University of Queensland, Room 817, Health Sciences Building, Royal Brisbane \& Women's Hospital, Herston, QLD 4029, Australia. ${ }^{3}$ Department of Biostatistics, School of Public Health, University of Washington, Seattle, WA 98198, USA.

Received: 13 November 2013 Accepted: 21 October 2014 Published: 26 October 2014

\section{References}

1. Williams H, Stewart A, von Mutius E, Cookson W, Anderson HR: Is eczema really on the increase worldwide? J Allergy Clin Immunol 2008, 121(4):947-954. e915.

2. Pearce N, Ait-Khaled N, Beasley R, Mallol J, Keil U, Mitchell E, Robertson C: Worldwide trends in the prevalence of asthma symptoms: phase III of the International Study of Asthma and Allergies in Childhood (ISAAC). Thorax 2007, 62(9):758-766.

3. Falade AG, Olawuyi JF, Osinusi K, Onadeko BO: Prevalence and severity of symptoms of asthma, allergic rhinoconjunctivitis, and atopic eczema in 6- to 7-year-old Nigerian primary school children: the international study of asthma and allergies in childhood. Med Princ Pract 2004, 13(1):20-25.

4. Asher MI, Montefort S, Bjorksten B, Lai CK, Strachan DP, Weiland SK, Williams $\mathrm{H}$ : Worldwide time trends in the prevalence of symptoms of asthma, allergic rhinoconjunctivitis, and eczema in childhood: ISAAC phases one and three repeat multicountry cross-sectional surveys. Lancet 2006, 368(9537):733-743.

5. Lee SL, Wong W, Lau YL: Increasing prevalence of allergic rhinitis but not asthma among children in Hong Kong from 1995 to 2001 (Phase 3 International study of asthma and allergies in childhood). Pediatr Allergy Immunol 2004, 15(1):72-78.

6. Arshad SH, Tariq SM, Matthews S, Hakim E: Sensitization to common allergens and its association with allergic disorders at age 4 years: a whole population birth cohort study. Pediatrics 2001, 108(2):E33.

7. Stevenson MD, Sellins S, Grube E, Schroer K, Gupta J, Wang N, Khurana Hershey GK: Aeroallergen sensitization in healthy children: racial and socioeconomic correlates. J Pediatr 2007, 151(2):187-191.

8. Chen Y, Rennie D, Cormier Y, Dosman J: Association between obesity and atopy in adults. Int Arch Allergy Immunol 2010, 153(4):372-377.

9. Hancox RJ, Milne BJ, Poulton R, Taylor DR, Greene JM, McLachlan CR, Cowan JO, Flannery EM, Herbison GP, Sears MR: Sex differences in the relation between body mass index and asthma and atopy in a birth cohort. Am J Respir Crit Care Med 2005, 171(5):440-445.

10. Ouyang F, Kumar R, Pongracic J, Story RE, Liu X, Wang B, Xing H, Li Z, Zhang W, Fang Y, Zhang S, Xu X, Wang X: Adiposity, serum lipid levels, and allergic sensitization in Chinese men and women. J Allergy Clin Immunol 2009, 123(4):940-948. e910.

11. Husemoen LL, Glumer C, Lau C, Pisinger C, Morch LS, Linneberg A Association of obesity and insulin resistance with asthma and aeroallergen sensitization. Allergy 2008, 63(5):575-582.

12. Visness CM, London SJ, Daniels JL, Kaufman JS, Yeatts KB, Siega-Riz AM, Liu AH, Calatroni A, Zeldin DC: Association of obesity with IgE levels and allergy symptoms in children and adolescents: results from the 
National health and nutrition examination survey 2005-2006. J Allergy Clin Immunol 2009, 123(5):1163-1169. 1169 e1161-1164.

13. Jarvis D, Chinn S, Potts J, Burney P: Association of body mass index with respiratory symptoms and atopy: results from the European community respiratory health survey. Clin Exp Allergy 2002, 32(6):831-837.

14. Chen $Y$, Dales $R$, Jiang $Y$ : The association between obesity and asthma is stronger in nonallergic than allergic adults. Chest 2006, 130(3):890-895.

15. Ma J, Xiao L, Knowles SB: Obesity, insulin resistance and the prevalence of atopy and asthma in US adults. Allergy 2010, 65(11):1455-1463.

16. Van Gysel D, Govaere E, Verhamme K, Doli E, De Baets F: Body mass index in Belgian schoolchildren and its relationship with sensitization and allergic symptoms. Pediatr Allergy Immunol 2009, 20(3):246-253.

17. Sybilski AJ, Raciborski F, Lipiec A, Tomaszewska A, Lusawa A, Furmanczyk K, Krzych-Falta E, Komorowski J, Samolinski B: Obesity - a risk factor for asthma, but not for atopic dermatitis, allergic rhinitis and sensitization. Public Health Nutr 2014,:1-7 [Epub ahead of print].

18. Giltay EJ, Fonk JC, von Blomberg BM, Drexhage HA, Schalkwijk C, Gooren LJ: In vivo effects of sex steroids on lymphocyte responsiveness and immunoglobulin levels in humans. J Clin Endocrinol Metab 2000, 85(4):1648-1657.

19. Govaere E, Van Gysel D, Massa G, Verhamme KM, Doli E, De Baets F: The influence of age and gender on sensitization to aero-allergens. Pediatr Allergy Immunol 2007, 18(8):671-678.

20. Strachan DP, Harkins LS, Johnston ID, Anderson HR: Childhood antecedents of allergic sensitization in young British adults. J Allergy Clin Immunol 1997, 99(1 Pt 1):6-12.

21. Linneberg A, Nielsen NH, Madsen F, Frolund L, Dirksen A, Jorgensen T: Factors related to allergic sensitization to aeroallergens in a crosssectional study in adults: The Copenhagen Allergy Study. Clin Exp Allergy 2001, 31(9):1409-1417.

22. Omenaas E, Bakke P, Elsayed S, Hanoa R, Gulsvik A: Total and specific serum IgE levels in adults: relationship to sex, age and environmental factors. Clin Exp Allergy 1994, 24(6):530-539.

23. Jarvis D, Chinn S, Luczynska C, Burney P: The association of smoking with sensitization to common environmental allergens: results from the European community respiratory health survey. J Allergy Clin Immunol 1999, 104(5):934-940.

24. Wuthrich B, Schindler C, Medici TC, Zellweger JP, Leuenberger P: IgE levels, atopy markers and hay fever in relation to age, sex and smoking status in a normal adult Swiss population. SAPALDIA (Swiss Study on Air Pollution and Lung Diseases in Adults) Team. Int Arch Allergy Immunol 1996, 111(4):396-402.

25. Barbee RA, Kaltenborn W, Lebowitz MD, Burrows B: Longitudinal changes in allergen skin test reactivity in a community population sample. J Allergy Clin Immunol 1987, 79(1):16-24.

26. Linneberg A, Nielsen NH, Madsen F, Frolund L, Dirksen A, Jorgensen T: Smoking and the development of allergic sensitization to aeroallergens in adults: a prospective population-based study. The Copenhagen allergy study. Allergy 2001, 56(4):328-332.

27. Hancox RJ, Welch D, Poulton R, Taylor DR, McLachlan CR, Greene JM, Sears MR: Cigarette smoking and allergic sensitization: a 32-year population-based cohort study. J Allergy Clin Immunol 2008, 121(1):38-42. e33.

28. Fantuzzi G: Adipose tissue, adipokines, and inflammation. J Allergy Clin Immunol 2005, 115(5):911-919. quiz 920.

29. Hofstetter A, Schutz $Y$, Jequier E, Wahren J: Increased 24-hour energy expenditure in cigarette smokers. N Engl J Med 1986, 314(2):79-82.

30. Collins LC, Cornelius MF, Vogel RL, Walker JF, Stamford BA: Effect of caffeine and/or cigarette smoking on resting energy expenditure. Int J Obes Relat Metab Disord 1994, 18(8):551-556

31. Dallosso HM, James WP: The role of smoking in the regulation of energy balance. Int J Obes (Lond) 1984, 8(4):365-375.

32. Perkins KA, Epstein LH, Stiller RL, Fernstrom MH, Sexton JE, Jacob RG Solberg R: Acute effects of nicotine on hunger and caloric intake in smokers and nonsmokers. Psychopharmacology (Berl) 1991, 103(1):103-109.

33. Froom P, Melamed S, Benbassat J: Smoking cessation and weight gain. J Fam Pract 1998, 46(6):460-464.

34. Caan B, Coates A, Schaefer C, Finkler L, Sternfeld B, Corbett K: Women gain weight 1 year after smoking cessation while dietary intake temporarily increases. J Am Diet Assoc 1996, 96(11):1150-1155.

35. Perkins KA: Weight gain following smoking cessation. J Consult Clin Psychol 1993, 61(5):768-777.
36. Perkins KA: Effects of tobacco smoking on caloric intake. Br J Addict 1992, 87(2):193-205

37. WHO: Guidelines for the Conduct of Tobacco Smoking Surveys for the General Population. In Geneva, Switzerland: World Health Organization; 1983. Document WHO/SMO/83.

38. WHO: Report of a WHO Expert Committee Technical Report Series. In Geneva: World Health Organization; 1995. Physical Status: The Use and Interpretation of Anthropometry.

39. Zhou BF: Predictive values of body mass index and waist circumference for risk factors of certain related diseases in Chinese adults-study on optimal cut-off points of body mass index and waist circumference in Chinese adults. Biomed Environ Sci 2002, 15(1):83-96.

40. Gupta RS, Springston EE, Smith B, Warrier MR, Pongracic J, Holl JL: Geographic variability of childhood food allergy in the United States. Clin Pediatr 2012, 51(9):856-861.

41. Sopori M: Effects of cigarette smoke on the immune system. Nat Rev Immunol 2002, 2(5):372-377.

42. Geng Y, Savage SM, Razani-Boroujerdi S, Sopori ML: Effects of nicotine on the immune response. II. Chronic nicotine treatment induces T cell anergy. J Immunol 1996, 156(7):2384-2390.

43. Prentice AM, Jebb SA: Beyond body mass index. Obes Rev 2001, 2(3):141-147.

44. Romero-Corral A, Montori VM, Somers VK, Korinek J, Thomas RJ, Allison TG, Mookadam F, Lopez-Jimenez F: Association of bodyweight with total mortality and with cardiovascular events in coronary artery disease: a systematic review of cohort studies. Lancet 2006, 368(9536):666-678.

45. Kim JH, Shim KW, Yoon YS, Lee SY, Kim SS, Oh SW: Cigarette smoking increases abdominal and visceral obesity but not overall fatness: an observational study. PLoS One 2012, 7(9)::45815.

doi:10.1186/1471-2458-14-1105

Cite this article as: Luo et al:: Effect modification by gender and smoking status on the association between obesity and atopic sensitization in Chinese adults: a hospital-based case-control study. BMC Public Health 2014 14:1105.

\section{Submit your next manuscript to BioMed Central and take full advantage of:}

- Convenient online submission

- Thorough peer review

- No space constraints or color figure charges

- Immediate publication on acceptance

- Inclusion in PubMed, CAS, Scopus and Google Scholar

- Research which is freely available for redistribution 